\title{
Experiência homossexual no contexto escolar
}

\section{Homosexual experience in the school context}

\author{
Anderson Ferrari ${ }^{1}$
}

\begin{abstract}
RESUMO
Neste artigo, partimos da utilização da carta de uma estudante adolescente à sua professora de Ciências, atribuindo a essa relação e à Escola sentidos atravessados por saber/poder. Uma carta que nos convida a olhar como vamos nos constituindo como sujeitos de desejo e como vamos acionando saberes para sermos capazes de produzir saberes sobre nós mesmos, tomando-nos como objeto de investigação. Dessa maneira, a questão que se coloca como foco deste artigo é, então, o que faz dos sujeitos, sujeitos de uma sexualidade específica, o que faz dos sujeitos, homossexuais. Trata-se de uma questão atual, que parte da atualidade para questionar a ideia de experiência homossexual como o encontro tenso entre os jogos de verdade, poder e subjetividades. Eis a tensão que nos faz reconhecer-nos como sujeitos sexuais.

Palavras-chave: experiência; sexualidades; conhecimento; subjetividade; educação.
\end{abstract}

\begin{abstract}
In this article, we start discussing a letter from a teenage student to her Science teacher, attributing to this relation and to the school meanings pervaded by knowledge/power. This letter invites us to think how we are constructed as subjects of desire and how we activate knowledge in order to produce the knowledge about ourselves, taking ourselves as an object of investigation. In this way, the focal question of this article is what makes subjects, subjects of a specific sexuality, what makes a homosexual subject. This is a contemporary question, one that starts at the present in order to question the idea of the homosexual experience as a tense encounter between
\end{abstract}

DOI: $10.1590 / 0104-4060.36461$

1 Universidade Federal de Juiz de Fora. Departamento de Educação. Juiz de Fora, Minas Gerais, Brasil. R. José Lourenço Kelmer, Campus Universitário - São Pedro. CEP: 36037-000. 
truth, power and subjectivities, a tension that makes us recognize ourselves as sexual subjects.

Keywords: experience; sexualities; knowledge; subjectivity; education.

\section{Introdução}

Quero começar esta escrita recuperando e situando uma carta que chegou às minhas mãos por intermédio de uma integrante do meu grupo de pesquisa ${ }^{2}$. Uma carta que foi escrita por uma adolescente, estudante de escola pública, e direcionada à sua professora de Ciências. Podemos identificar de imediato as dúvidas no que se refere ao que está vivendo e uma certa ansiedade em sanar as questões que dizem dela. Porém, quero tomar essa correspondência como um convite e, nesse sentido, uma escrita que nos incita a olhar para além dela, estabelecendo assim um diálogo com as questões que discutimos no interior do grupo e que dizem da constituição dos sujeitos em meio às relações entre sexualidade-verdade-subjetividade, sobretudo no interior das escolas. Em função disso, a professora solicitou a autorização da aluna para trazer a carta para que eu pudesse tomá-la como objeto de análise deste artigo. Portanto, ela é um material empírico isolado, mas que se integra a um movimento que vem atingindo o grupo como um todo: estamos sendo acionados pelas escolas para discutir as diferentes expressões de homossexualidades que estão presentes no seu interior. Somos procurados com frequência por diretoras, professoras e mesmo por alunos e alunas para discutir e esclarecer as questões que dizem das sexualidades nas escolas, para "ajudar" a compreendê-las e a lidar com elas. A carta apresentada é parte desse movimento.

Tia. Dúvidas, perguntas, não sei nem como falar. Tenho todas as dúvidas que você possa imaginar. Eu nunca falei de sexo com ninguém, nem sobre homem. Imagina sobre mulher. A única coisa que escuto é que é errado e nojento. Claro que tenho vontade de saber como é. Igual não pensava que ia falar sobre sexo com minha professora, ainda mais sobre Lesbianismo. Quando toquei nessa menina para ela era uma brincadeira, mas para mim não. Eu já era abusada na época. Eu já tinha a mente diferente. $O$

2 O grupo de pesquisa e estudos a que faço referência é o GESED - Grupo de Pesquisa e Estudos em Gênero, Sexualidade, Educação e Diversidade, que engloba estudantes de graduação, pós-graduação, professores e professoras. 
que mais me irrita é que sinto vontade de beijar uma mulher, saber qual é a sensação porque eu toquei nela, mas não beijei. Agora eu acho que não teria nojo de beijar uma mulher tanto como tenho de homem. Só de lembrar o cara que abusou de mim me tocando é horrivel. Ficar coagida no canto de uma parede com um homem te apertando com força para você não fugir, num canto da parede me machuca. Mas só que já fiquei com meninos. Não cheguei até relação sexual, mas já beijei e tudo mais. Não sinto prazer por homem, vou te ser sincera. Já fui forçada a pôr a mão nos órgãos genitais de um homem, mas além de ser forçada, não senti nada. Já vi DVD pornográfico, mas não senti nada vendo homem, mas vendo mulher. Nos meus 15 anos eu quis ficar com um menino. A gente saiu da festa e fomos para um lugar, mais sozinhos. Além de não está sentindo muita coisa, ele estava bêbado e tentou me forçar. Ele tirou a calça dele e tentou tirar a minha roupa. Graças a deus eu consegui fugir dele. Ele queria isso no meio da rua. Então, tia, eu realmente detesto homem. Não gosto mesmo nem que me ponham a mão. Então eu sei que se eu casar não teria nem orgasmo com o meu marido. Prefiro ficar sozinha, mas apesar de muito desejo por tocar numa mulher novamente. Beijar, sentir alguma coisa. Se você quiser escrever sobre isso [...] sobre isso pelas bases que você conhece pelo que você sabe sobre Lesbianismo, fica a vontade. Eu acho que pessoalmente é pior, porque eu teria muita vergonha de te ver falando sobre sexo comigo. Eu quero sim conhecer mais, só que de verdade quero parar de sentir desejo por mulheres. Eu dormi chorando porque não quero perder algumas pessoas que já estão me magoando nessa área e realmente não quero. Quero aprender a não ter desejo, mas quero mudar, entende?

Essa é uma carta encaminhada por uma menina adolescente que pode ser entendida como uma "revelação", como um "pedido de ajuda", de forma que esse entendimento, presente na escrita e atribuído por nós, convida-nos a problematizar esses sentidos para a menina e para nós mesmos numa perspectiva histórica das sexualidades. Estudando a história das sexualidades a partir de uma analítica do poder, Foucault (1988) nos ajuda a pensar como a noção de homossexualidade e de homossexual se vinculou à ideia de anormalidade, de doença e de uma certa experiência ${ }^{3}$ subjetiva. Nesse sentido, podemos questionar sobre o que faz desta menina, lésbica. Num movimento mais amplo, a questão que se coloca como foco deste artigo é, então, o que faz dos sujeitos

3 A noção de experiência atravessa todo o trabalho de Foucault e pode ser definida como dessubjetivação, ou seja, ela é parte do processo de subjetivação na medida em que é entendida como momento de transformação. 
de uma sexualidade específica, o que faz dos sujeitos, homossexuais. Trata-se de uma questão atual, que parte da atualidade, para colocar sob suspeita a ideia de experiência homossexual como o encontro tenso entre os jogos de verdade, poder e subjetividades (FOUCAULT, 2010a, 2010b); uma tensão que nos faz reconhecer-nos como sujeitos sexuais. Tomando a constituição dos sujeitos como central no seu trabalho, Foucault vai se dedicar a pensar e a problematizar os processos pelos quais nos tornamos o que somos, ou melhor, "o que estão (os outros) e estamos (nós) fazendo de nós mesmos?” (VEIGA-NETO, 2003, p. 12). Essa é uma problemática de investigação que me inspira neste artigo, uma vez que a carta da menina traz para a discussão a relação entre verdade, poder e subjetividade, ou seja, como vamos nos constituindo em meio aos saberes, atravessados por relações de poder e pela ação dos outros sobre nós e que somos capazes de empreender sobre nós mesmos. A escrita da carta é, então, nessa perspectiva, algo que diz desta menina de uma forma mais particular e solitária, mas que é potente, na medida em que escapa à pura subjetividade, fazendo com que outros meninos e outras meninas possam dialogar, cruzar e atravessar essa experiência.

Primeiramente, é importante iniciar este debate pensando-se nas condições de emergência dessa carta. As condições de emergência são uma preocupação de investigação de Foucault (1988) e nos incitam a olhar para o contexto de produção de determinadas ações, pensamentos, sujeitos, para suspeitar do que não nos chama atenção. Mais do que isso, esse termo reforça a perspectiva histórica de construção das palavras, dos pensamentos e dos sujeitos, de maneira que colocar em debate as condições de emergência da carta de uma aluna para sua professora é assumir o que ela diz de um tempo histórico. Assim, poderíamos nos perguntar por que correspondências desse tipo surgem neste momento e não em outro? Que sociedade temos hoje e que escolas e professores estão possibilitando esse tipo de relação entre alunos, sexualidades e escolas?

Essa carta não é um caso isolado. Cada vez mais, recebemos no GESED correspondências desse tipo, sejam elas advindas dos alunos e alunas ou das professoras ou mesmo das diretoras. No seu conjunto, são expressões de que o debate das homossexualidades está posto na nossa sociedade e de que as escolas participam dele. É possível dizer que o debate em torno das sexualidades e mais especificamente das homossexualidades está em plena construção e disputa no momento atual. Um contexto que nos aproxima da defesa foucaultiana (FOUCAULT, 1988) de que somos levados a produzir diferentes discursos em torno das sexualidades, constituindo-as. Nesse sentido, temos a ação dos grupos gays que, desde o final da década de 1970 e mais intensamente na década de 1980 (muito em função da epidemia do HIV/Aids que foi capaz de estabelecer um diálogo entre saúde, prevenção e educação), vêm lutando para desconstruir ima- 
gens negativas das homossexualidades, ao mesmo tempo em que se organizam em torno da construção de imagens positivas. Nessa luta política, a Educação é parte importante. Por isso as escolas e a formação docente são espaços de disputa e de ação dos grupos. No caso específico de Juiz de Fora, temos ainda para fortalecer essa vinculação um dos mais importantes eventos nacionais de encontro da comunidade LGBT (Lésbicas, Gays, Bissexuais, Travestis, Transexuais e Transgêneros) e que repercute nas escolas - o Rainbow Fest - um evento anual, com duração de uma semana, que movimenta a cidade com debates nas diferentes áreas do conhecimento e que culmina numa grande festa de eleição da Miss Gay Brasil.

Nos últimos anos essas ações se fortaleceram com o Programa Brasil sem Homofobia e, em que pese sua desaceleração atual, ele serviu, nos anos anteriores, para fomentar um projeto que há muito vinha partindo de uma demanda dos professores e professoras. Desde a década de 1990, o MGM (Movimento Gay de Minas), numa ação isolada, vem organizando um encontro para professores e professoras, como parte da programação do Rainbow Fest, intitulado "Homossexualidades e Escolas", destinado ao debate da temática homossexual e a suas relações com a Educação. Assim eram discutidas essas relações nas diferentes áreas da Educação tais como: Currículo, Formação Docente, Gênero e Sexualidades, Gestão Escolar e Educação Infantil. Foi um encontro de dois dias que, ao final, revelava a necessidade de algo mais profundo, que foi possibilitado a partir do edital do Programa Brasil sem Homofobia, que, por sua vez, possibilitou a organização de duas edições do Curso de Capacitação "Lidando com as Homossexualidades", entre 2007 e 2008. Essas ações repercutiram nas escolas e na cidade como um todo. Podemos apontar como um dos seus resultados mais eficazes o debate permanente em torno das homossexualidades e a visibilidade dessa comunidade, inclusive nas escolas.

Somada a isso, temos, ainda, a organização do nosso grupo de pesquisa - GESED, que desde 2010 vem se reunindo, envolvendo estudantes de Graduação e de Pós-graduação, professores e professoras da rede pública. É um grupo diretamente vinculado à UFJF (Universidade Federal de Juiz de Fora), que vem produzindo livros e seminários, tomando para si a responsabilidade de discutir, ampliar e manter o debate.

Por um lado, essas ações vêm demonstrando a impossibilidade de falar de homossexualidade no singular, ressaltando a necessidade de pensar, olhar e lidar com as homossexualidades sempre no plural, de forma que não é possível pensar num tipo de homossexual típico, mas numa multiplicidade de homossexualidades, problematizando e afetando a maneira das escolas lidarem com as homossexualidades. Muitas vezes aceitamos e possibilitamos um tipo de homossexual, quase sempre vinculado a um modelo heteronormativo, ou seja, 
aquele homossexual sério, casado, que não se mostra, "que se dá o respeito". Portanto, o desafio é olhar e lidar com o "outro", diferente na sua outridade, e não transformar o "outro" naquilo que se quer que ele seja.

Por outro lado, podemos dizer também que esse contexto tem possibilitado e aumentado a existência de professores e professoras diferentes. Professores homossexuais e professoras lésbicas que se colocam no interior das escolas, que estabelecem, com isso, outros tipos de relação com alunos e alunas. Professores e professoras que já olham para a sala de aula e para o contexto escolar como um todo, entendendo que esses espaços dizem mais do que relações de conteúdo e que estão acontecendo outras coisas para além dos conteúdos. Professores e professoras que, independentemente de suas orientações sexuais, estão interessados em discutir e construir outras formas de ser e estar, outros tipos de escolas e, por isso, procuram os cursos que promovemos. Professores que, ao se colocarem nesse movimento, possibilitam que alunos e alunas se sintam mais à vontade para escrever ou procurá-los para falar de si, como ocorreu na carta que estamos tomando como foco de análise neste artigo.

Poderíamos acrescentar a tudo isso o fato de o debate em torno das homossexualidades ser algo social e cultural e que diz deste momento histórico. Fruto de construção que não é de agora, ele é parte do nosso cotidiano. Ele está nas escolas, porque está na sociedade de forma geral. Ele está nas mídias. Basta um olhar atento para os noticiários, para as telenovelas, para os programas da grade da rede aberta de televisão, para constatar que ele é quase diário. Há um movimento de mão dupla que organiza e constrói esse debate. Isso está na televisão, porque está na sociedade; e está na sociedade, porque está na televisão, de maneira que há uma retroalimentação entre esses espaços. É um movimento que nos obriga ao olhar com cuidado para tudo isso, uma vez que, independentemente de a escola realizá-lo, participar ou não dele, ele está sendo construído e chega às escolas. No entanto, a escola, por ser o lugar por excelência de conhecimento, não é o espaço do senso comum, mesmo que ele insista em aparecer pelas falas dos alunos e alunas. A escola é o local de problematização do senso comum, do que não nos assusta mais porque naturalizamos. E dizer das homossexualidades é dizer desse senso comum, dessa forma de conhecer que organiza o social, que invade as escolas e que constrói sujeitos. Assumir a postura de problematização é mais do que olhar para o que está nas salas de aula, é questionar a forma de conhecer, é dar um passo atrás para olhar de outra forma (MARSHALL, 2008). Quando a professora assume a correspondência, quando dá lugar a ela, assumindo que não "sabe", mas que quer saber e "ajudar", vai demonstrando que está nesse movimento, nessas condições de emergência que a estão constituindo como professora também. 


\section{Experiência e experiência homossexual}

Discutir as homossexualidades no contexto escolar, tomando a carta de uma adolescente como detonadora dessa problematização, é uma forma de assumir que essas expressões, discursos, comportamentos e práticas estão inseridos numa história da sexualidade (FOUCAULT, 1988). Portanto me parece importante nos determos nessas duas noções tão familiares e recentes - sexualidades e homossexualidades - para dar lugar à análise do contexto teórico e prático que dá significados a elas e ao qual elas são associadas. O uso do termo homossexualidade se estabeleceu em relação a outros fenômenos como mostramos anteriormente. Podemos ir mais além do quadro desenhado na introdução deste artigo e dizer que as homossexualidades são herdeiras de um tempo - o século XIX. Não quero dizer com isso que esse tempo se reproduz ainda hoje, mas quero dar lugar à atualidade, para pensar o que somos hoje e construir análises muito parciais para as relações entre homossexualidades e escolas, através da história do pensamento, ou melhor, por meio da análise histórica das relações entre nossas formas de pensar e nossas práticas na sociedade. Por isso a carta da aluna me parece importante para dar voz a um movimento que vem se multiplicando nas escolas. Meninos e meninas buscam a escola como um espaço de entendimento para o que estão vivendo no campo das sexualidades, atribuindo a ela o lugar do conhecimento e vinculando diretamente a questão das sexualidades e das homossexualidades ao saber. Não é à toa que a menina inicia sua carta com essa aproximação entre saber, jogos de verdade e subjetividades. "Dúvidas, perguntas, não sei nem como falar. Tenho todas as dúvidas que você possa imaginar. Eu nunca falei de sexo com ninguém, nem sobre homem. Imagina sobre mulher. A única coisa que escuto é que é errado e nojento. Claro que tenho vontade de saber como é."

Há uma vinculação importante entre "o que eu sei", que vem de um saber coletivo, social, algo que se aproxima do senso comum (que é uma forma de conhecer), e "o que dizem" ("que escuto"), as dúvidas e como me vejo. A menina nos aproxima dessa tensão entre os jogos de verdade, poder e subjetividade, capaz de nos constituir como sujeitos de uma experiência. Quando nascemos, entramos em contato com um mundo já organizado, com saberes que nos organizam e que nos constituem, de maneira que somos muito mais fruto desses saberes do que produtores dele. A menina se vê no diálogo com esses saberes, que, no entanto, não a convencem. Ela procura a escola para saber mais ou para ter acesso a outro tipo de saberes que não aquele que escuta e que diz o que é "errado" e "nojento". As homossexualidades são inventadas em meio a conhecimentos 
diversos, tanto aqueles relacionados à sexualidade como mecanismo biológico de reprodução quanto mecanismos variados de comportamentos, sejam eles individuais ou coletivos, como, por exemplo, a ação dos grupos gays organizados (FERRARI, 2005). Saberes que também se relacionam a um conjunto de regras e de normas que se fundamentam nas mais diversas instituições. Assim, esses saberes que dizem das homossexualidades estão ligados à religião, à justiça, aos movimentos sociais, à medicina e, cada vez mais, à educação. Enfim, criam-se situações que dizem das diferentes maneiras como os indivíduos são levados a dar sentido e valor aos seus desejos, comportamentos, prazeres e ações.

Trata-se, em suma, de ver como se constituiu, nas sociedades ocidentais modernas, uma "experiência", de modo que os indivíduos puderam reconhecer-se como sujeitos de uma "sexualidade" que [se] abre para campos muito diversos de conhecimento e que se articula a um sistema de regras cuja força de coerção é muito variável. Portanto, história da sexualidade como experiência - se entendermos por experiência a correlação, em uma cultura, entre campos de saber, tipos de normatividade e formas de subjetividade. (FOUCAULT, 2006, p. 193).

Na carta a menina se pensa através da análise dos elementos do desejo e coloca em circulação saberes, discursos e pensamentos que mais do que relacionar, constitui o desejo como prenúncio do "errado", do desvalorizado. Com isso, o desejo tem a sua função reconhecida não somente nos atos sexuais, mas também em todos os campos do comportamento da menina. É possível pensar como a carta revela um tipo de atitude que aprendemos a desenvolver conosco e que diz da relação entre Eu - Verdade - Confissão - Desejo - Corpo. Somos ensinados a buscar no nosso corpo os nossos desejos e vamos confessando, pelo menos para nós mesmos, aquilo que sentimos e vamos nomeando e dando sentido a tudo isso como nossas "verdades". Assim, vamos nos constituindo em meio a esses saberes e transformando a nós mesmos como objetos de conhecimento e de investigação. Somos capazes de dizer o que somos e de falar das nossas "verdades" a partir dos nossos desejos. Os nossos desejos nos situam, nos dão lugares de sujeitos.

No caso da menina, o desejo é lido como um elemento constitutivo de algo errado e nojento e, portanto, proibido. Há uma luta entre a vontade e o medo de viver o desejo, que diz de um processo de decifração daquilo que ela é. Nesse sentido, o corpo e aquilo que se passa nele, através dele, a partir dele é objeto de análise. A menina e o seu corpo se transformam em seu próprio objeto de análise, 
de dor e prazer, de conhecimento e medo, de vontade e dúvida, de liberdade e negação, de busca de ajuda e necessidade de explicação e de entendimento. O corpo é examinado para saber que coisas "proibidas", "erradas" se preparam e se produzem nele. Essa menina é tomada de tal forma por determinados discursos e saberes que se torna difícil pensar o desejo numa perspectiva do prazer. O desejo e o prazer são presumidos, de maneira que o corpo se torna problema.

Na carta é possível perceber uma busca por conhecer-se a si mesma, que passa pelo conhecimento de seu desejo. Ela parece experimentar uma situação paradoxal de conhecimento do seu desejo, associado a um "supersaber", como nos lembra Foucault:

[...] isto é, um saber de qualquer forma excessivo, um saber ampliado, um saber ao mesmo tempo intenso e extenso da sexualidade, não no plano individual, mas no plano cultural, no plano social, em formas teóricas ou simplificadas. Creio que a cultura ocidental foi surpreendida por uma espécie de desenvolvimento, de hiperdesenvolvimento do discurso da sexualidade, da teoria da sexualidade, da ciência sobre a sexualidade, do saber sobre a sexualidade. (FOUCAULT, 2006, p. 58).

A nossa sociedade, como herdeira de um movimento próprio das sociedades ocidentais do final do século XIX, parece ainda presa a essa situação paradoxal, que é o desenvolvimento pelo sujeito de seu próprio desejo - algo individual que se encontra com algo social e cultural - que é o fenômeno de "supersaber" em torno da sexualidade.

Esses dois fenômenos - de desconhecimento da sexualidade pelo próprio sujeito e de supersaber sobre a sexualidade na sociedade - não são fenômenos contraditórios. Eles coexistem efetivamente no Ocidente, e um dos problemas é certamente saber de que modo, em uma sociedade como a nossa, é possível haver essa produção teórica, essa produção especulativa, essa produção analítica sobre a sexualidade no plano cultural geral e, ao mesmo tempo, um desconhecimento do sujeito a respeito de sua sexualidade. (FOUCAULT, 2006, p. 59).

Podemos pensar que existe toda uma produção social de discursos sobre a sexualidade, porque as pessoas, assim como a menina da carta, continuam buscando (o que equivaleria dizer que continuam a ignorar) o que se passa 
com elas no campo da sexualidade, do desejo, da verdade. Não é à toa que ela busca a escola e a professora. A carta, de certa forma, é uma busca de entendimento do desconhecido, ou outra forma de conhecer e pensar que não seja essa ligada ao "errado" e que suscite "nojo", ou seja, que não seja essa do que já conhecemos em torno das homossexualidades e que nos situa, nos fornece uma posição de sujeito.

Nesse sentido, o problema não é o desconhecido pelo sujeito, mas a superprodução de saber social e cultural em torno de um saber coletivo sobre a sexualidade. As questões postas pela carta desencadeiam um movimento extenso, ou seja, a menina busca a professora, que me procura. Diante disso, podemos pensar a nossa sociedade e a nossa dificuldade (em que a escola está implicada) em ensinar o amor como uma arte, de forma que não ensinamos a fazer amor, a obter prazer, a dar e receber prazer. Esses discursos que dizem da iniciação sexual, da arte erótica, existem, mas só que de forma clandestina e entre amigos. Acabamos investindo na Ciência Sexual, constituindo discursos sobre a sexualidade das pessoas e não sobre o prazer delas. Abandonamos o prazer das pessoas, não falamos dele, ou pelo menos não falamos dele no sentido de potencializá-lo, mas tomamos o prazer para "prender" as pessoas nas suas "verdades", ou seja, para saber "qual é a verdade dessa coisa que, no indivíduo, é seu sexo ou sua sexualidade: verdade do sexo e não intensidade do prazer". (FOUCAULT, 2006, p. 61).

Pensar as condições de emergência da carta significa pensar que ainda está muito presente em nós a ideia de que se deve ter um verdadeiro sexo, uma única sexualidade, o que mais nos aprisiona do que nos liberta. Muitos poderiam entender que a saída para a menina está na compreensão de "sua" sexualidade mais prazerosa com mulheres, de forma que assumir-se lésbica significaria sua liberdade. No entanto, em muitas situações, assumir uma identidade homossexual tem representado uma absolutização dessa identidade, de maneira que a homossexualidade muito mais aprisiona do que liberta. É um contexto que faz a menina procurar sua verdade naquilo que consegue ler, identificar e significar como sensação do corpo, ao mesmo tempo em que nos possibilita entender a carta e suas ansiedades também inscritas a partir dos significados para isso que está sentindo e vivendo. Os discursos e seus significados nos constituem. Estamos todos de acordo com o fato de que entre sexualidade e verdade existem relações complexas, obscuras e essenciais.

O que estamos advogando com isso é que pensar a sexualidade numa perspectiva histórica e como uma experiência nos convida a colocar sob suspeita um esquema de pensamento que toma a sexualidade como uma invariante (FOUCAULT, 2006). Falar, portanto, da sexualidade como uma experiência historicamente singular une essa expressão dos sujeitos ao sentido de experiência. 
Assim também podemos analisar as homossexualidades a partir das correlações entre os três eixos que compõem a experiência: os jogos de verdade e formação de saberes, que juntos se referem às definições de sexualidades e das homossexualidades; as relações de poder que atravessam e regulam suas práticas; e, por último, as subjetividades, ou seja, os processos pelos quais os sujeitos podem e devem se reconhecer como sujeitos de determinadas sexualidades.

A atuação desses três eixos na constituição da experiência da sexualidade parece organizar a atuação da menina sobre si mesma e seu movimento em direção à escola como local para desvendar esse saber e, em última análise, responder à questão "quem sou eu"? A noção de desejo e de diferentes desejos, assim como de um sujeito desejante, é algo já aceito em nossa sociedade. No entanto isso não é algo dado, mas resultado de uma história que foi capaz de ir construindo essa relação entre desejo, verdade, subjetividade, o que nos faz olhar para as práticas através das quais os indivíduos são chamados a se voltar para si mesmos, a se confessar, a se decifrar, a se reconhecer e se assumir como sujeitos de um determinado desejo (e quase sempre somente de um). São processos capazes de conduzir esses sujeitos a estabelecerem de si para consigo mesmos um enquadramento que permite a eles descobrir, a partir do corpo e do desejo, a "verdade de seu ser". Nesse sentido, diz a menina: "Quando toquei nessa menina para ela era uma brincadeira, mas para mim não. Eu já era abusada na época. Eu já tinha a mente diferente. O que mais me irrita é que sinto vontade de beijar uma mulher, saber qual é a sensação porque eu toquei nela, mas não beijei". Ela busca nas suas ações e nas sensações indícios de um desejo singular, um desejo que é só dela, que a singulariza. No entanto, esse mesmo desejo que a singulariza, que a diferencia, também serve para aproximá-la de um coletivo, um desejo que faz dela uma menina diferente de outras meninas, mas, ao mesmo tempo, igual a tantas outras. Um desejo que diferencia e enquadra. Como todos nós somos levados a exercer sobre nós mesmos e sobre os outros uma hermenêutica do desejo? Como podemos fazer das experiências de nós mesmos algo capaz de nos transformar em sujeitos de desejo?

\section{E a escola em meio a tudo isso?}

A escola é acionada pela menina. Assim, o que foi escrito não é uma carta qualquer, mas uma carta direcionada. Direcionada à professora de Ciências, que, no momento em questão, representa uma instituição - a escola. Ao fazer 
isso, ou seja, ao direcionar a carta à professora de Ciências e à escola, a menina implica a escola nesse processo de tornar-se e reconhecer-se como sujeito de desejo, esse processo que liga saber, poder e subjetividade. A menina põe em jogo a articulação entre as práticas discursivas, saberes e subjetividades. Ela contrapõe o que sabe, o que escuta dos "outros" sobre o que deve ser a "verdade", visto que a escola é reconhecidamente o local do saber e, portanto, da verdade. Ela inicia a carta afirmando: "tenho todas as dúvidas que você possa imaginar". A carta, de certa forma, é uma maneira de sanar essas dúvidas, reforçando a relação professor-aluno, atravessada por esses lugares de dúvidas e de resolução delas pelo professor. E continua: "a única coisa que escuto é que é errado e nojento. Claro que tenho vontade de saber como é. Igual não pensava que ia falar de sexo com minha professora, ainda mais sobre lesbianismo”. É interessante pensar como as questões ligadas à sexualidade estão organizadas por manifestações do poder e como podemos pensar em diversas relações nesse sentido, a partir do que lemos. Uma primeira questão diz dessa relação: a "única coisa que escuta", nessa relação que parte do outro e que me diz sobre o que sinto e quem sou. Contudo, as estratégias diante desses saberes e poderes estão abertas, o que pode representar outra forma de organização. Nesse sentido, ela escreve a carta, ela busca saber, ela aciona a professora e implica a escola nesse jogo. Mais do que isso, ela vai de encontro a técnicas racionais que mantêm o exercício dos poderes. Ela desloca, com a carta, esse exercício de poder - dos outros e do que escuto para a professora e para a escola, levando em conta a vontade de saber - mantendo, assim, ao que parece, a busca por maneiras de estabelecer relações consigo mesma e por meio das quais ela vem se constituindo e se reconhecendo como sujeito. Não quero dizer com isso que há uma intencionalidade consciente na carta da menina, mas que esse processo de sanar dúvidas está implicado na vontade de outro tipo de saber e que ele pode servir para a construção de novas formas de pensar e ser.

Nesse processo de se reconhecer, a menina vai enumerando diversos eventos que podem ser lidos como indícios de sua verdade. Ela mesma inicia esse processo na tentativa de se explicar à professora. Podemos pensar que a professora deveria saber o que se passou com a menina e as sensações que a organizam, já que a carta foi direcionada a ela, atribuindo-lhe a função de sanar as dúvidas. Diante da necessidade de escrever à professora, a menina se confessa e busca na sua trajetória o que consegue reconhecer como indício de sua verdade. Como esses jogos de verdade, saberes e subjetividades atravessam e organizam a constituição de si mesma como sujeito? Para colocar isso em prática, a menina se transforma no seu próprio objeto de investigação, na busca por sua história como sujeito desejante. E vai construindo sua história, vai buscando desejo ou não desejo em sua história. "Quando toquei nessa menina, para ela era uma 
brincadeira, mas para mim, não”. Ela busca a sua verdade, a verdade dos seus sentidos e práticas. Busca também outros indícios que a aproxima dessa relação com o desejo e sua verdade. "Eu já era abusada na época. Eu já tinha a mente diferente. O que mais me irrita é que sinto vontade de beijar uma mulher, de saber qual é a sensação porque eu já toquei nela, mas não beijei. Agora eu acho que não teria nojo de beijar uma mulher tanto como eu tenho de homem".

$\mathrm{Na}$ busca por sua história como sujeito de desejo, essa menina vai nos contando "uma história que não seria do que poderia existir de verdadeiro nos conhecimentos, mas sim uma análise dos 'jogos de verdade', dos jogos do verdadeiro e do falso através dos quais o ser se constitui historicamente como experiência, ou seja, como podendo e devendo ser pensado". (FOUCAULT, 2006 , p. 195). Ela nos interroga sobre as diferentes maneiras que encontramos para nos reconhecer como sujeitos de desejo. Que jogos de verdade e que instituições e saberes acionamos para nos reconhecermos como sujeitos de desejo? A escola é um desses lugares e espaços em que esses jogos de verdade estão presentes e nos organizando como sujeitos de desejo. Em alguns momentos da carta isso fica mais evidente. "Se você quiser escrever sobre isso [...] sobre isso pelas bases que você conhece pelo que você sabe sobre Lesbianismo, fica a vontade. Eu acho que pessoalmente é pior, porque eu teria muita vergonha de te ver falando sobre sexo comigo". A professora é colocada no lugar do saber, ela é chamada e envolvida nessa problemática do sujeito e seu desejo. Mais do que colocar a professora diante dessa relação entre sujeito e desejo, ela faz a professora ter contato com a sua formação, se perguntar se está "preparada" para esse exercício de poder do qual é chamada a participar. Nesse sentido o trabalho nas escolas está cercado de desafios e potencialidades. Trata-se do desafio de conceber esses temas em torno das sexualidades não com uma tradução ou comentário das proibições, mas como algo que pertence à essência e que estaria ligado a uma verdade absoluta. Nesse caso surge a potencialidade de pensar outras relações no interior da escola, em torno das sexualidades, no exercício do seu poder, como práticas de liberdade.

O que a carta aponta como questão para a escola é o desafio de colocar sob suspeita as formas de pensamento, a história do pensamento no que diz respeito às sexualidades. A menina não quer apenas sanar suas dúvidas, ela quer outra forma de pensar, de conhecer, de lidar com elas. Ela quer que a escola busque outra forma de operar com essa relação entre jogos de verdade, poder e subjetividades. Desta forma, parece-me que a carta pode ser inscrita num convite à escola para operar com as sexualidades de outra forma e não esta da interdição das expressões sexuais e da exigência de austeridade sexual. Tanto é que a menina autoriza a professora a escrever sobre o seu caso. Talvez para que ele possa servir para construir outras bases de conhecimento, capazes de 
suscitar, a partir das experiências e sob outros parâmetros, outras formas de problematização, de maneira que a carta e a história desta menina possam servir como objeto de questionamento, de cuidado e de elemento de reflexão. Nesse sentido, podemos perguntar por que as práticas dos prazeres são questionadas a partir das questões do corpo, do envolvimento com pessoas do mesmo sexo e da verdade? Como as práticas, as sensações e os comportamentos foram pensados e, ainda, são problematizados a partir da experiência moral?

Experiência e Moral são dois conceitos que nos inspiram na carta escrita e no movimento que estamos fazendo de tomá-la para pensar a sexualidade não como desenvolvimento de algo dado, mas como um processo histórico e relacional, o que significa dizer que ela se constitui em meio a uma rede que envolve corpo, prazer, normas, proibições, fugas, saberes e poderes. Essa forma de olhar potencializa as articulações entre experiência e moral. Segundo Castro (2009), Foucault, na sua trajetória de investigação, descobre um sentido de experiência como aquela que não está na origem do sujeito, de maneira que a experiência não funda o sujeito, mas está ligada à dessubjetivação. Esse processo de dessubjetivação está ligado a esse sentido de experiência como aquela que á capaz de fazer o sujeito desprender-se de si mesmo, de modo que ele não seja mais o mesmo. É a ideia de uma experiência limite. Nesse sentido, a carta parece uma forma de dizer isso, pois a menina que viveu o que viveu não é capaz de voltar a ser o que era antes. A aproximação com a outra menina foi capaz de fazê-la desprender-se de si mesma, o que representou para ela uma experiência limite. No entanto esse limite é sempre diretamente ligado a um conjunto de valores e regras de conduta a que estamos sujeitos numa sociedade, o que constitui um sentido de moral. Assim, experiência, dessubjetivação/subjetivação e moral estão imbricadas na constituição dos sujeitos.

Entende-se "moral" como um conjunto de valores e de regras de conduta que são propostas aos indivíduos e aos grupos por meio de diversos aparelhos prescritivos, como podem ser a família, as instituições educativas, as Igrejas, etc. Ocorre que essas regras e valores sejam bem explicitamente formulados em uma doutrina coerente e em um ensinamento explícito. Mas ocorre também que sejam transmitidos de maneira difusa e que, longe de formarem um conjunto sistemático, constituam um jogo complexo de elementos que se compensam, se corrigem, se anulam em certos pontos, permitindo, dessa forma, compromissos ou escapatórias. (FOUCAULT, 2006, p. 211). 
A partir dessa citação, podemos pensar a moral como um conjunto prescritivo de código moral, mas também podemos pensá-la como o comportamento real dos indivíduos diante desse código, que pode ser resumido minimamente a dois aspectos: o compromisso com esses códigos ou a identificação e vivência das possibilidades de escapatória. Voltando para o exemplo da carta, podemos perceber uma contradição. Por um lado, a menina inicia a carta assumindo que tem dúvidas e quer conhecer outra forma de pensar e, por isso, destina a correspondência à professora, aproximando-se da possibilidade de fuga do que está posto, do código que classifica as homossexualidades como "errado" e "nojento" e do qual ela também compartilha, em certa medida. Por outro lado, no final da carta, ela parece manter o compromisso com esse código de valores. Ela diz: "Eu quero sim conhecer mais, só que de verdade quero parar de sentir desejo por mulheres. Eu dormi chorando porque não quero perder algumas pessoas que já estão me magoando nessa área e realmente não quero. Quero aprender a não ter desejo, mas quero mudar, entende?". Ela revela todo o jogo complexo que está posto entre o compromisso e a escapatória a essa moral que está diretamente ligada às práticas de si e aos nossos processos de subjetivação. Ao mesmo tempo em que demonstra uma vontade de romper com esse código de moral, ela tem dificuldades de concretizar isso e recorre à escola. Ela apresenta uma discussão para a professora que não está prevista. Ela traz algo da vida para dentro da escola. Ela exige outro tipo de professora, como aquela que deve discutir os significados da sexualidade.

Enfim, a escrita que está organizando a carta é uma vontade de saber que está cada vez mais presente no que se refere às homossexualidades, ou seja, aquela mais obstinada e praticada na direção de desprender-se de si mesmo, de desprender-se de como se conhece. É uma atitude que recorre à escola como esse lugar de saber, que será capaz de dar "armas" para distanciar-se da perspectiva de assimilação do que convém conhecer. A menina reivindica o seu direito de vivenciar, de experimentar o que, em nosso pensamento, pode ser alterado. Algo que pode ser modificado e que está diretamente relacionado à necessidade de pensar diferente, para poder experimentar o que é "errado", "nojento" e, portanto, estranho. Romper o silêncio é envolver a escola buscando outro caminho que não seja esse de legitimar o que "já sabe". Em última análise, podemos pensar que é uma solicitação atual de uma "nova" escola, como aquela em que se pode tentar saber como e em que medida é possível pensar e ser diferente do que se é. Ela poderia continuar pensando silenciosamente, mas prefere chamar a escola e a professora para sua problemática, que mais do que a problemática da sexualidade, diz da maneira como ela se coloca para nós, atravessada por esse jogo de saber, poder, prazer, verdade e subjetividade. Ao romper o silêncio, ela demonstra que existem momentos na nossa construção em que a questão de 
saber se é possível pensar diferente daquilo que está posto, como comumente se pensa, e a de se perceber e se pensar de outra maneira são fundamentais para continuar a ver e refletir.

\section{REFERÊNCIAS}

CASTRO, Edgardo. Vocabulário Foucault. Um percurso pelos seus temas, conceitos e autores. Belo Horizonte: Autêntica, 2009.

FERRARI, Anderson. Quem sou eu? Que lugar ocupo? Grupos Gays, Educação e a Construção do Sujeito Homossexual. Tese (Doutorado em Educação) - Unicamp. Campinas, 2005.

FOUCAULT, Michel. História da Sexualidade I. A vontade de saber. Rio de Janeiro: Edições Graal, 1988.

.Ética, sexualidade, política. Rio de Janeiro: Forense Universitária, 2006.

. A hermenêutica do sujeito. Curso dado no Collège de France (1981-1982). São Paulo: Editora WMF Martins Fontes, 2010.

. O governo de si e dos outros. Curso dado no Collège de France (1982-1983). São Paulo: Editora WMF Martins Fontes, 2010a.

MARSHALL, James D. Michel Foucault: pesquisa educacional como problematização. In: PETERS, Michel A.; BESLEY, Tina (Orgs.). Por que Foucault? Novas diretrizes para a pesquisa educacional. Porto Alegre: Artmed, 2008, p. 25-40.

VEIGA-NETO, Alfredo. Foucault \& a Educação. Belo Horizonte: Autêntica, 2003.

Texto recebido em 09 de maio de 2014.

Texto aprovado em 19 de maio de 2014. 